\title{
Efeitos de diferentes fontes de concentrado sobre o consumo e a produção de cordeiros na fase de terminação
}

\author{
Camila Celeste Brandão Ferreira Ítavo ${ }^{1}$, Maria da Graça Morais², Luís Carlos Vinhas Ítavo ${ }^{3}$, \\ Andréa Roberto Duarte Lopes de Souza ${ }^{4}$, Maurílio Massaharu Oshiro ${ }^{4}$, Fábio Arguelo \\ Biberg $^{4}$, Ciniro Costa ${ }^{5}$, Clóves Cabreira Jobim ${ }^{6}$, Beatriz Lempp ${ }^{2}$

\footnotetext{
${ }^{1}$ Zootecnista, Mestre em Ciência Animal, Aluna de Pós-Graduação em Zootecnia da UNESP Botucatu, SP.

2 Pós-Graduação em Ciência Animal da Universidade Federal de Mato Grosso do Sul, Campo Grande-MS.

3 Pós-Graduação em Desenvolvimento Local da Universidade Católica Dom Bosco, Campo Grande-MS

4 Graduação - Universidade Federal de Mato Grosso do Sul, Campo Grande-MS.

5 Pós-Graduação em Zootecnia da Universidade Estadual de Maringá, PR.

${ }^{6}$ Pós-Graduação em Zootecnia da UNESP Botucatu, SP.
}

RESUMO - Objetivou-se avaliar os efeitos dos grãos de milho e sorgo, secos ou ensilados úmidos, sobre o consumo de nutrientes e o desempenho de cordeiros em confinamento. O confinamento teve duração de 77 dias e foi dividido em dois períodos: no primeiro (35 dias), utilizou-se como volumoso capim-elefante (Pennisetum purpureum Schum.), na proporção de 50:50 e, no segundo (42 dias), feno de capim-braquiária (Brachiaria brizantha), na proporção de 30:70. Os animais foram distribuídos aleatoriamente em blocos, de acordo com o peso, conforme os tratamentos, que consistiram de diferentes fontes de alimento concentrado energético: silagem de grão úmido de milho; silagem de grão úmido de sorgo; grão seco de milho; e grão seco de sorgo. Os consumos de MS, em g/dia, em \% PV e em $\mathrm{PV}^{0,75}$, não diferiram entre os animais alimentados com grãos de milho e sorgo, secos ou úmidos, e capimelefante cv. Napier, com média de $920,79 \mathrm{~g} / \mathrm{dia} ; 3,59 \%$ e $81,01 \mathrm{~g} / \mathrm{kg}$ PV 0,75 . Os grãos de milho e de sorgo ensilados úmidos, quando comparados aos grãos secos, proporcionaram melhor ganho de peso $(0,17$ vs 0,13 e 0,19 vs $0,13 \mathrm{~kg} /$ dia), conversão (5,57 vs 6,37 e 5,05 vs 6,86) e eficiência alimentar (17,95 vs 15,69 e 19,79 vs 14,74). O uso de grãos de sorgo, secos e úmidos, em dietas à base de feno de capim-braquiária, resultou em maior ganho de peso, ao passo que o de grãos secos de sorgo promoveu melhor conversão alimentar. Na proporção volumoso:concentrado 50:50, os grãos de milho e sorgo ensilados proporcionaram melhores ganhos de peso, conversão e eficiência alimentar que os grãos secos. Em dietas com maior participação de concentrado (proporção 30:70), fontes de maior degradabilidade (milho) influenciaram negativamente o ambiente ruminal, resultando em desempenho inferior.

Palavras-chave: confinamento, desempenho, ovinos

\section{Effects of different concentrate sources on intake and production of finishing lambs}

\begin{abstract}
This study was conducted to evaluate the effects of high moisture corn and high moisture sorghum versus corn and sorghum grains on intake and production of feedlot lambs. Confinement lasted 77 days and was divided in two periods as follows: in the first 35 days elephant grass (Pennisetum purpureum Schum.) was used in a forage:concentrate ratio of 50:50 while Brachiaria-grass (Brachiaria brizantha) hay was used in a forage:concentrate of 30:70 in the remaining 42 days. Animals were blocked by weight and randomly assigned to one of four treatments: high moisture corn, high moisture sorghum, corn grain, or sorghum grain. Intakes of DM expressed in $\mathrm{g} / \mathrm{day}$, in $\% \mathrm{BW}$ or in $\mathrm{g} / \mathrm{kg} \mathrm{BW}^{0.75}$ did not differ among treatments averaging $920.79 \mathrm{~g} /$ day, $3.59 \%$, and $81.01 \mathrm{~g} / \mathrm{kg} \mathrm{BW}{ }^{0.75}$. The weight gain ( 0.17 vs. 0.13 and $\left.0.19 v s .0 .13 \mathrm{~kg} / \mathrm{day}\right)$, feed conversion (5.57 vs. 6.37 and 5.05 vs. 6.86), and feed efficiency (17.95 vs. 15.69 and 19.79 vs. 14.74) values were higher for animals fed high moisture corn and high moisture sorghum grain compared to corn and sorghum grains, respectively. Lambs fed Brachiaria hay supplemented with either high moisture sorghum or sorghum grain had greater weight gain while those fed sorghum grain showed improved feed conversion. In diets with forage:concentrate ratio of 50:50 feeding high moisture corn and high moisture sorghum resulted in increased weight gains, feed conversion, and feed efficiency compared to corn and sorghum grains. In diets with higher proportion of concentrate (forage:concentrate ratio of 30:70) the reduction in animal production may be explained by the rapid degradation of corn leading to poor ruminal environment.
\end{abstract}

Key Words: feedlot, performance, sheep

\section{Introdução}

A produção de ovinos tem crescido em todo país, notadamente na Região Centro-Oeste, observando-se cres- cente utilização de confinamentos, visando principalmente à oferta de carne durante a entressafra. Entretanto, o sucesso da produção em confinamento depende de vários fatores, incluindo o potencial genético dos animais, o manejo sanitário 
do rebanho, a nutrição, as práticas de alimentação e a visão de mercado de insumos (Carvalho et al., 2003).

Nesse contexto, a ensilagem de grãos úmidos pode contribuir significativamente para melhoria dos índices de produtividade, pois, além de apresentar valor nutricional, consiste em importante constituinte de rações, em decorrência da redução em seu custo de produção (Jobim et al., 2001), ocasionada pela maximização do uso da terra, pela redução de perdas qualiquantitativas no campo e na armazenagem e pela eliminação das etapas de pré-limpeza e secagem, quando utilizado na forma de grãos secos (Jobim \& Reis, 2001; Costa et al., 1999).

Entretanto, Jobim \& Reis (2001), em sua revisão, apresentaram algumas desvantagens da ensilagem de grãos de cereais, uma vez que o material ensilado não possui flexibilidade de comercialização, é altamente sensível à deterioração aeróbia e necessita de mistura diária dos ingredientes na dieta.

Há algum tempo, tem-se estudado a possibilidade de substituição dos grãos secos por grãos de cereais ensilados úmidos em dietas totais para frangos de corte (Sartori et al., 2002); leitões (Oliveira et al., 2004); eqüinos (Santos et al., 2002); bovinos de corte (Costa et al., 1997, citados por Costa et al., 1999; Berndt et al., 2002) e bovinos de leite (Peixoto et al., 2003). Segundo Costa et al. (1999), animais submetidos a dietas contendo silagens de grãos úmidos de milho e de sorgo apresentam maior eficiência alimentar que aqueles alimentados com grãos secos.

Reis et al. (2001) estudaram o desempenho de cordeiros em confinamento consumindo silagens de grãos úmidos de milho ou de grãos de milho hidratados em substituição aos grãos de milho secos da dieta e verificaram que as silagens proporcionaram maior eficiência em ganho de peso, provavelmente em razão de sua maior digestibilidade.

Almeida Jr. et al. (2002) não encontraram diferenças no desempenho de cordeiros creep-feeding submetidos a diferentes níveis de substituição $(0,50$ e $100 \%)$ dos grãos secos por silagem de grãos úmidos de milho na ração. Os autores afirmaram que a opção entre as formas de armazenamento deve ser feita a partir de indicadores econômicos do processo produtivo e que, possivelmente, o aleitamento tenha mascarado a superioridade da silagem de grãos úmidos de milho.

Segundo Phillippeau et al. (1999), a taxa e a extensão da fermentação ruminal variam significativamente de acordo com a fonte e o processamento do cereal. Além disso, o local de digestão do amido tem implicações nos produtos finais da digestão, como ácidos graxos voláteis no rúmen e glicose no intestino delgado, e, portanto, afeta a eficiência de utilização metabólica por ruminantes.
Jobim \& Reis (2001), em revisão, relataram que a colheita do milho úmido para silagem, em relação ao grão seco, constitui uma vantagem, pois pode exercer efeito benéfico sobre a digestibilidade da matéria seca. Esse efeito pode ser explicado pelo fato de que o grão é colhido antes da maturação, quando ainda não possui matriz protéica totalmente formada. De acordo com Phillippeau et al. (1999), a matriz protéica limita a digestão ruminal do amido, de modo que a colheita antecipada favorece a disponibilidade do amido.

Costa et al. (1999) também ressaltaram que o amido em contato com água, como é o caso dos grãos úmidos de milho e de sorgo, sofre expansão reversível até que a água represente aproximadamente $50 \%$ do peso total, com conseqüente solubilização da matriz protéica. Possivelmente, o rápido declínio do $\mathrm{pH}$, característico de silagens de grãos úmidos, também auxilia no processo de solubilização da matriz protéica e na maior digestibilidade dos grãos, como resultado do tratamento ácido do material.

Nesse contexto, objetivou-se avaliar os efeitos dos grãos de milho e de sorgo, secos ou ensilados úmidos, como concentrado energético da dieta total sobre os consumos de matéria seca, proteína bruta e nutrientes digestíveis totais e o desempenho de cordeiros em confinamento.

\section{Material e Métodos}

O experimento foi conduzido na Universidade Federal de Mato Grosso do Sul, em Campo Grande-MS, no período de março de 2003 a junho de 2004. O plantio do sorgo (cv. Rancheiro) e do milho safrinha foi realizado em março de 2003 e a colheita e ensilagem, em julho de 2003.

O milho e o sorgo foram colhidos na fase de maturação fisiológica, com 63,97 e 69,56\% de MS, respectivamente. Após processamento, os grãos foram ensilados em tambores plásticos, tipo tonel com capacidade de 200 litros, que permaneceram vedados, em local coberto e à temperatura ambiente, por 240 dias.

Foram utilizados 24 cordeiros machos, desmamados, sem raça definida, provenientes da estação de nascimento de outubro a dezembro de 2003, apresentando peso médio de $20,05 \pm 3,25 \mathrm{~kg}$ ao início do experimento. Os animais receberam coccidiostático e vacina contra clostridiose. $\mathrm{Na}$ chegada e durante a estadia dos animais, foram realizadas vermifugações estratégicas, por meio de análises de OPG (contagem de ovos por grama de fezes).

No confinamento, os animais foram alojados em baias individuais de $3 \mathrm{~m}^{2}$, com piso ripado, providas de comedouros para alimentação e suplementação mineral, e bebedouro. Os animais receberam água e sal mineral à vontade. 
Como volumoso, foram utilizados, ambos triturados, capim-elefante (Pennisetum purpureum Schum. cv. Napier), de 50 a 90 dias de idade, durante o primeiro período (35 dias), na relação volumoso:concentrado de 50:50, e feno de capimbraquiária (Brachiaria brizantha), durante o segundo período de avaliação (42 dias), na relação volumoso:concentrado de 30:70, totalizando 77 dias de confinamento.

As análises químicas foram realizadas no Laboratório de Nutrição Animal da Universidade Federal de Mato Grosso do Sul. Os alimentos foram analisados quanto aos teores de matéria seca(MS) e proteína bruta (PB), segundo metodologia descrita por Silva \& Queiroz (2002). Foram considerados os valores de nutrientes digestíveis totais (NDT) do capimelefante, do feno de capim-braquiária, do farelo de soja e dos grãos secos de milho e sorgo determinados por Valadares Filho et al. (2002) e os valores de NDT das silagens de grãos úmidos obtidos por Ítavo (2004). A composição química dos alimentos utilizados encontra-se na Tabela 1.

$\mathrm{O}$ concentrado, à base de farelo de soja e milho ou sorgo, secos ou ensilados úmidos, foi formulado para atender às exigências nutricionais dos cordeiros (AFRC, 1993), estimando-se ganho de peso de $150 \mathrm{~g} /$ dia no primeiro período (120 g de PB, $550 \mathrm{~g}$ de NDT e $800 \mathrm{~g}$ de MS/dia, para animais com peso corporal de $20 \mathrm{~kg}$ ) e $200 \mathrm{~g} / \mathrm{dia}$ ( $150 \mathrm{~g}$ de PB, $875 \mathrm{~g}$ de NDT e $1200 \mathrm{~g}$ de MS/dia, para animais com peso corporal de $30 \mathrm{~kg}$ ) no segundo período. As dietas foram balanceadas e as rações foram isoprotéicas e isoenergéticas. As composições percentual e química das rações experimentais (na matéria seca) contendo capim-elefante
Tabela 1- Teores médios de MS, PB e NDT dos alimentos utilizados durante o confinamento

Table 1 - Contents of DM, CP, and TDN of the feedlot feeds

\begin{tabular}{|c|c|c|c|}
\hline \multirow[t]{2}{*}{$\begin{array}{l}\text { Ingrediente } \\
\text { Feed }\end{array}$} & \multirow{2}{*}{$\begin{array}{l}\text { MS } \\
D M \\
(\%)\end{array}$} & $\begin{array}{l}\mathrm{PB} \\
C P\end{array}$ & $\begin{array}{l}\mathrm{NDT}^{1} \\
T D N^{1}\end{array}$ \\
\hline & & \multicolumn{2}{|c|}{$\begin{array}{l}(\% \mathrm{MS}) \\
(\% D M)\end{array}$} \\
\hline Capim-elefante & 26,61 & 6,62 & 52,91 \\
\hline $\begin{array}{l}\text { Elephantgrass } \\
\text { Feno de capim-braquiária } \\
\text { Brachiaria hay }\end{array}$ & 83,83 & 5,60 & 49,29 \\
\hline Farelo de soja & 82,67 & 48,57 & 81,04 \\
\hline $\begin{array}{l}\text { Soybean meal } \\
\text { Uréia }\end{array}$ & 98,00 & 280,00 & - \\
\hline $\begin{array}{l}\text { Urea } \\
\text { Milho grão seco } \\
\text { Corn grain }\end{array}$ & 85,83 & 7,92 & 85,65 \\
\hline $\begin{array}{l}\text { Milho grão úmido } \\
\text { High moisture corn }\end{array}$ & 61,46 & 5,76 & 78,54 \\
\hline $\begin{array}{l}\text { Sorgo grão seco } \\
\text { Sorghum grain }\end{array}$ & 83,68 & 8,24 & 78,43 \\
\hline $\begin{array}{l}\text { Sorgo grão úmido } \\
\text { High moisture sorghum }\end{array}$ & 63,87 & 7,92 & 82,00 \\
\hline
\end{tabular}

${ }^{1}$ Valores estimados por Valadares Filho et al. (2002) e Ítavo (2004).

1 Values estimated from Valadares Filho et al. (2002) and İtavo (2004).

encontram-se na Tabela 2 e das rações contendo feno de capim-braquiária, na Tabela 3.

Os animais foram distribuídos aleatoriamente, de acordo com o peso, em blocos, segundo os tratamentos: (1) capimelefante ou feno + silagem de grão de milho úmido, (2) capim-elefante ou feno + silagem de grão de sorgo úmido; (3) capim-elefante ou feno + grão seco de milho; e (4) capimelefante ou feno + grão de sorgo seco.

Tabela 2 - Composição percentual dos ingredientes e teores médios de MS, em porcentagem (\%), PB e NDT, em porcentagem da MS (\% da MS), das rações experimentais à base de capim-elefante (Pennisetum purpureum Schum.) utilizadas na relação volumoso:concentrado de 50:50

Table 2 - Ingredient composition (\%) and contents of DM, in \%, CP, and TDN (\% of DM), of the experimental diets containing elephantgrass (Pennisetum purpureum Schum.) in a 50:50 forage:concentrate ratio

\begin{tabular}{|c|c|c|c|c|}
\hline \multirow[t]{2}{*}{ Itens } & \multicolumn{2}{|c|}{$\begin{array}{l}\text { Grãos de milho } \\
\text { Corn grains }\end{array}$} & \multicolumn{2}{|c|}{$\begin{array}{l}\text { Grãos de sorgo } \\
\text { Sorghum grains }\end{array}$} \\
\hline & $\begin{array}{l}\text { Secos } \\
\text { Dried }\end{array}$ & $\begin{array}{c}\text { Ensilados } \\
\text { Ensiled }\end{array}$ & $\begin{array}{l}\text { Secos } \\
\text { Dried }\end{array}$ & $\begin{array}{c}\text { Ensilados } \\
\text { Ensiled } \\
\end{array}$ \\
\hline $\begin{array}{l}\text { Capim-elefante }(\%) \\
\text { Elephantgrass }\end{array}$ & 50,00 & 50,00 & 50,00 & 50,00 \\
\hline $\begin{array}{l}\text { Grão (\%) } \\
\text { Grain }\end{array}$ & 35,00 & 35,00 & 35,00 & 35,00 \\
\hline $\begin{array}{l}\text { Farelo de soja (\%) } \\
\text { Soybean meal }\end{array}$ & 14,80 & 14,80 & 14,80 & 14,80 \\
\hline $\begin{array}{l}\text { Uréia }(\%) \\
\text { Urea } \\
\text { Dieta total } \\
\text { Total diet }\end{array}$ & 0,20 & 0,20 & 0,20 & 0,20 \\
\hline $\begin{array}{l}\text { MS (\%) } \\
D M\end{array}$ & 55,78 & 47,25 & 55,02 & 48,09 \\
\hline $\begin{array}{l}\mathrm{PB}(\% \mathrm{MS}) \\
C P(\% D M)\end{array}$ & 13,83 & 13,07 & 13,94 & 13,83 \\
\hline $\begin{array}{l}\text { NDT }(\% \mathrm{MS}) \\
T D N(\% D M)\end{array}$ & 68,43 & 65,94 & 65,90 & 67,15 \\
\hline
\end{tabular}


Tabela 3 - Composição percentual dos ingredientes e teores médios de MS, PB e NDT das rações experimentais à base de feno de capim-braquiária (Brachiaria brizantha) utilizadas na relação volumoso:concentrado de 30:70

Table 3 - Ingredient composition and contents of DM (\%), CP, and TDN (\% of DM), of the experimental diets containing Brachiaria hay (Brachiaria brizantha) in a 30:70 forage:concentrate ratio

\begin{tabular}{|c|c|c|c|c|}
\hline \multirow[t]{2}{*}{ Item } & \multicolumn{2}{|c|}{$\begin{array}{l}\text { Grãos de milho } \\
\text { Corn grains }\end{array}$} & \multicolumn{2}{|c|}{$\begin{array}{l}\text { Grãos de sorgo } \\
\text { Sorghum grains }\end{array}$} \\
\hline & $\begin{array}{l}\text { Secos } \\
\text { Dried }\end{array}$ & $\begin{array}{c}\text { Ensilados } \\
\text { Ensiled } \\
\end{array}$ & $\begin{array}{l}\text { Secos } \\
\text { Dried }\end{array}$ & $\begin{array}{l}\text { Ensilados } \\
\text { Ensiled }\end{array}$ \\
\hline $\begin{array}{l}\text { Feno de capim-braquiária (\%) } \\
\text { Brachiaria hay }\end{array}$ & 30,00 & 30,00 & 30,00 & 30,00 \\
\hline $\begin{array}{l}\text { Grão }(\%) \\
\text { Grain }\end{array}$ & 45,40 & 40,00 & 45,80 & 43,00 \\
\hline $\begin{array}{l}\text { Farelo de soja }(\%) \\
\text { Soybean meal } \\
\text { Dieta total } \\
\text { Total diet }\end{array}$ & 24,60 & 30,00 & 24,20 & 27,00 \\
\hline $\begin{array}{l}\text { MS (\%) DM } \\
\text { PB (\% MS) }\end{array}$ & $\begin{array}{l}84,45 \\
17,22\end{array}$ & $\begin{array}{l}74,53 \\
18,55\end{array}$ & $\begin{array}{l}83,48 \\
17,21\end{array}$ & $\begin{array}{l}74,93 \\
18,20\end{array}$ \\
\hline $\begin{array}{l}C P(\% D M) \\
\text { NDT }(\% \mathrm{MS}) \\
T D N(\% D M)\end{array}$ & 73,61 & 70,52 & 70,32 & 71,93 \\
\hline
\end{tabular}

A alimentação foi fornecida diariamente às 8 e $16 \mathrm{~h}, a d$ libitum, de forma a permitir sobras de aproximadamente $10 \%$. Os alimentos fornecidos e as sobras foram quantificados e amostrados diariamente, elaborando-se amostras compostas, que foram armazenadas em sacos plásticos identificados e congeladas a $-20^{\circ} \mathrm{C}$ para posteriores análises laboratoriais.

Os tratamentos foram arranjados em um delineamento em blocos casualizados, com seis repetições por tratamento, e analisados segundo o modelo estatístico:

$$
\mathrm{Y}_{\mathrm{ijk}}=\mu+\mathrm{V}_{\mathrm{i}}+\mathrm{T}_{\mathrm{j}}+\mathrm{VT}_{\mathrm{ij}}+\mathrm{e}_{\mathrm{ijk}}
$$

em que $Y_{i j k}=$ observação k, referente ao tratamento com volumoso $\mathrm{i}$, associado ao tratamento com tipo de concentrado energético $\mathrm{j} ; \mu=$ constante geral; $\mathrm{V}_{\mathrm{i}}=$ efeito do volumoso na dieta $\mathrm{i}, \mathrm{i}=1 \mathrm{e} 2 ; \mathrm{T}_{\mathrm{j}}=$ efeito do tipo de concentrado energético $\mathrm{i}, \mathrm{i}=1, \ldots 4 ; \mathrm{VT}_{\mathrm{ij}}=$ efeito da interação entre volumoso i e concentrado energético $\mathrm{j}$; $\mathrm{e}_{\mathrm{ijk}}=$ erro aleatório associado a cada observação $Y_{\mathrm{ijk}}$.

Os dados de consumo de matéria seca e desempenho dos animais foram avaliados por meio de análises de variância, utilizando-se o Sistema de Análises Estatísticas e Genéticas - SAEG (UFV, 2000) e as médias comparadas pelo teste Tukey, a 5\% de significância.

\section{Resultados e Discussão}

As médias dos consumos de MS (CMS), PB (CPB) e NDT (CNDT), em g/dia, CMS em porcentagem do peso vivo $(\% \mathrm{PV})$ e em gramas por $\mathrm{kg}$ de peso metabólico $\left(\mathrm{PV}^{0,75}\right)$, da conversão alimentar, da eficiência alimentar (em \%), dos pesos inicial e final, do ganho total (em kg) e do ganho médio diário (GMD), em gramas/dia, de cordeiros em confinamento recebendo dietas à base de capim-elefante (Pennisetum purpureum Schum.) e grãos de milho ou sorgo, secos ou ensilados úmidos, são apresentadas na Tabela 4.

Os consumos de MS, em gramas por dia, em \% PV e em $\mathrm{g} / \mathrm{kg} \mathrm{PV}^{0,75}$, não diferiram $(\mathrm{P}>0,05)$ entre os animais alimentados com grãos de milho e de sorgo, secos ou ensilados úmidos, nas dietas à base de capim-elefante cv. Napier. Esses valores são superiores aos obtidos por Garcia et al. (2000), que avaliaram o desempenho de cordeiros Texel x Bergamácia, Texel x Santa Inês e Santa Inês puros e encontraram consumo de matéria seca, em porcentagem do peso metabólico, de $72,00 \mathrm{~g} / \mathrm{kg} \mathrm{PV}^{0,75}$ para dietas à base de silagem de capim-elefante e milho desintegrado com palha e sabugo, milho moído e farelo de soja.

Todavia, os valores de consumo de MS em g/dia obtidos neste ensaio são semelhantes ao consumo de $800 \mathrm{~g}$ estimado pelo AFRC (1993) para cordeiros de $20 \mathrm{~kg}$ de PV com ganho médio esperado de $150 \mathrm{~g} /$ dia. A média de consumo das dietas obtida neste experimento foi de 3,6\% PV e pode ser considerada normal, em razão do ganho de peso no decorrer do período, em comparação ao peso corporal de $20 \mathrm{~kg}$, utilizado pelo AFRC (1993). Os consumos de proteína bruta $(\mathrm{CPB})$ e nutrientes digestíveis totais (CNDT) não foram influenciados pelos tratamentos nas dietas com relação volumoso:concentrado 50:50 (período 1), uma vez que eram isoprotéicas e isoenergéticas. Os tratamentos supriram as exigências de nutrientes sugeridas pelo AFRC (1993) para ganhos de $150 \mathrm{~g} / \mathrm{dia}$, sendo necessários $119 \mathrm{~g} /$ dia de PB e $550 \mathrm{~g} /$ dia de NDT. 
Todavia, apenas os tratamentos com grãos úmidos ensilados proporcionaram ganhos acima do esperado.

Os cordeiros alimentados com silagens de grãos úmidos de milho e de sorgo apresentaram os melhores resultados de conversão e eficiência alimentar $(\mathrm{P}<0,05)$. É possível que a ensilagem dos grãos tenha proporcionado maior quantidade de produtos finais da digestão, o que implica diretamente em maior eficiência de utilização metabólica dos animais (Phillipeau et al., 1999). Ressalta-se que somente as silagens de grãos úmidos proporcionaram ganho de peso superior ao predito pelo AFRC (1993), certamente em razão de sua metabolizabilidade decorrente das formas de armazenamento dos grãos.

Os ganhos de peso médios diários diferiram $(\mathrm{P}<0,05)$ entre os animais alimentados com diferentes tipos de silagem de grãos de milho e de sorgo, de modo que os grãos úmidos de milho e de sorgo proporcionaram ganhos de peso superiores aos dos grãos secos. Essa observação corrobora os relatos de Jobim \& Reis (2001), que afirmaram que a colheita do grão úmido para ensilagem, em relação ao grão seco, por ser realizada antes da formação da matriz protéica, constitui uma vantagem, pois pode exercer efeitos benéficos sobre a digestibilidade da matéria seca. Possivelmente, essa maior digestibilidade da matéria seca foi a principal responsável pelos maiores ganhos de peso médios dos animais alimentados com as silagens de grãos úmidos de milho e de sorgo. A ensilagem dos grãos úmidos de milho e de sorgo provavelmente favoreceu o aumento da digestibilidade destes grãos, por meio do rompimento da matriz protéica que envolve os grânulos de amido. Esse rompimento pode ter sido causado pela presença de ácidos orgânicos resultantes do processo fermentativo, os quais possibilitaram os valores de ganho de peso diário, conversão alimentar, eficiência alimentar e ganho de peso total para os animais alimentados com silagens de grãos.

Entretanto, Almeida Jr. et al. (2002) não encontraram diferença no desempenho de cordeiros em creep-feeding alimentados com diferentes níveis de silagens de grãos úmidos de milho em substituição aos grãos secos na dieta, com ganho de peso médio de $363,00 \mathrm{~g} / \mathrm{dia}$, superior ao obtidos neste ensaio. Todavia, no experimento supracitado, os cordeiros permaneceram em aleitamento, concomitantemente

Tabela 4 - Médias e coeficientes de variação dos consumos de matéria seca (CMS), em g/dia, \%PV e g/kg de peso metabólico (PV0,75), de nutrientes digestíveis totais (CNDT) e de proteína bruta (CPB), conversão alimentar, eficiência alimentar (em \%), pesos inicial e final, ganho total (em kg) e ganho médio diário (GMD), em gramas/dia, de cordeiros em confinamento recebendo dietas à base de capim-elefante (Pennisetum purpureum Schum.) e grãos de milho ou sorgo, secos ou ensilados úmidos

Table 4 - Means and coefficients of variation of intake of dry matter (IDM), in g/day, (\%BW) and g/kg of metabolic weight (BW $\left.{ }^{0.75}\right)$, total digestible nutrients (ITDN) and crude protein (ICP), feed conversion, feed efficiency (in \%), initial and final weights, total weight (in $\mathrm{kg}$ ) and average daily gain (ADG), in grams/day, for feedlot lambs fed diets with elephantgrass (Pennisetum purpureum Schum.) and different sources of grain

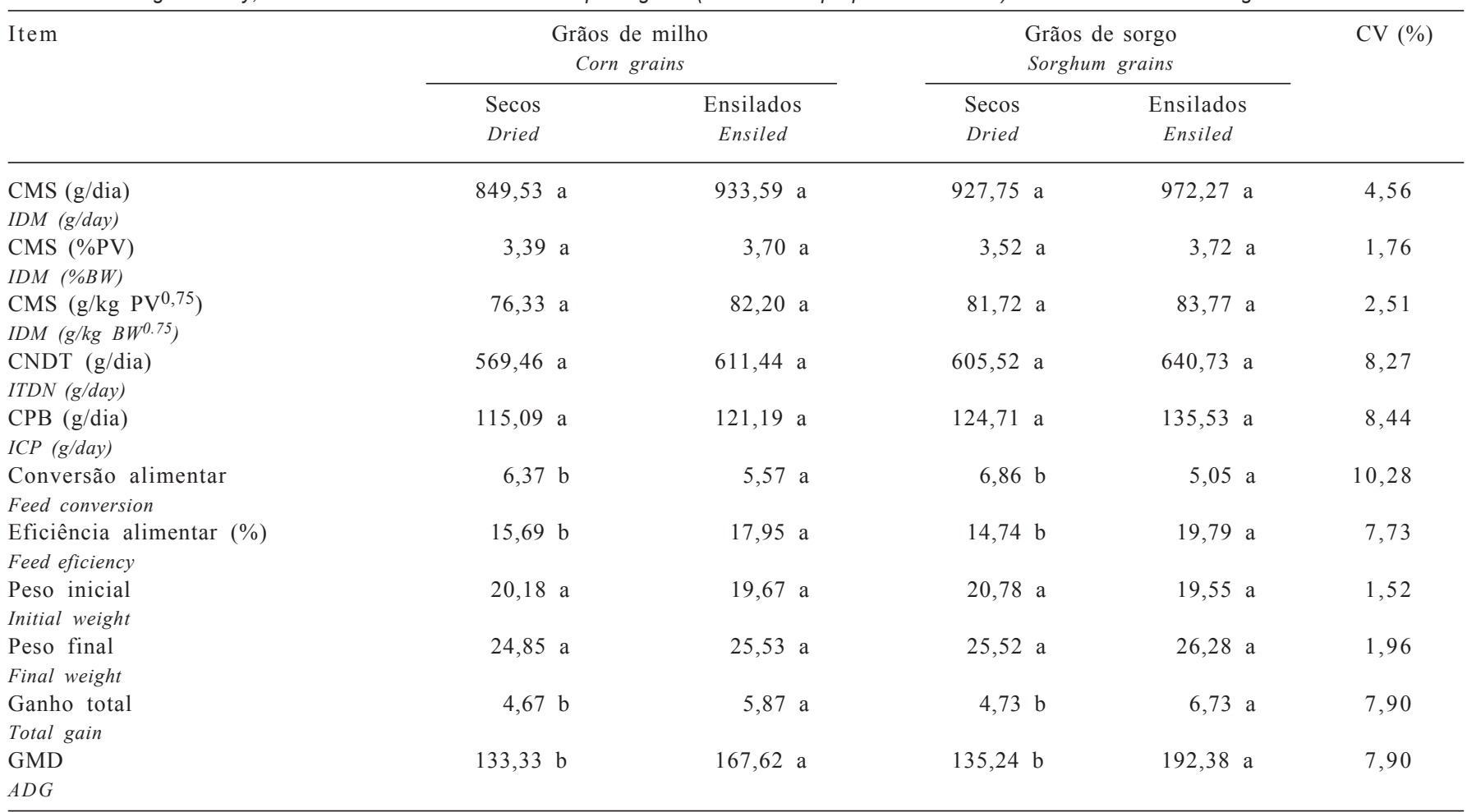

\footnotetext{
${ }^{1}$ Médias seguidas por letras iguais na mesma linha não diferem pelo teste Tukey $(\mathrm{P}>0,05)$.
}

${ }^{1}$ Means followed by the same letters, in the same row, did not differ $(P>0.05)$ by Tukey test. 
à ingestão de ração concentrada, e não sofreram estresse causado pela separação das mães, pelo transporte até o local e pelo manejo do confinamento.

As médias dos consumos de matéria seca (CMS), de proteína bruta (CPB) e de nutrientes digestíveis totais (CNDT), em gramas/dia, em porcentagem do peso vivo (\%PV) e em gramas por kg de peso metabólico $\left(\mathrm{PV}^{0,75}\right)$, da conversão alimentar, da eficiência alimentar (em \%), dos pesos inicial e final, do ganho total (em kg) e do ganho médio diário (GMD), em gramas/dia, dos cordeiros em confinamento recebendo dietas à base de feno de capim-braquiária (Brachiaria brizantha) e grãos de milho ou sorgo, secos ou ensilados úmidos, estão apresentadas na Tabela 5.

Os consumos de MS, em $\mathrm{g} /$ dia, diferiram $(\mathrm{P}<0,05)$ entre animais alimentados com diferentes tipos de silagem de grãos de milho e de sorgo, de modo que os grãos de milho, secos e ensilados úmidos, proporcionaram menores consumos de MS. Entretanto, na análise dos consumos de MS, em porcentagem do $\mathrm{PV}$ e do $\mathrm{PV}^{0,75}$, não foram detectadas diferenças significativas $(\mathrm{P}>0,05)$.

Os consumos de matéria seca em $\mathrm{g}$ /dia obtidos com a utilização de feno de capim-braquiária (Brachiaria brizantha), em associação a grãos de milho secos ou ensilados úmidos (Tabela 5), foram ligeiramente inferiores aos preditos pelo AFRC (1993), que propõe consumo mínimo de $1.200 \mathrm{~g}$ de $\mathrm{MS} /$ dia para ganhos esperados de $200 \mathrm{~g} / \mathrm{dia}$, o que justifica os menores ganhos de peso obtidos e está, provavelmente, relacionado à influência negativa dos grãos de milho no ambiente ruminal, decorrente da maior degradabilidade, confirmada pelo menor consumo. Os consumos de proteína bruta (CPB) e nutrientes digestíveis totais (CNDT) atenderam às exigências nutricionais para ganhos esperados de $200 \mathrm{~g} /$ dia em cordeiros com $30 \mathrm{~kg}$ de peso vivo, sugeridas pelo AFRC (1993), sendo $150 \mathrm{~g} /$ dia de proteína bruta e $875 \mathrm{~g} /$ dia de nutrientes digestíveis totais. Não houve diferenças significativas entre tratamentos para os consumos de PB e NDT, com médias de 200,35 e $228,45 \mathrm{~g} /$ dia para os tratamentos com grãos de milho e sorgo, respectivamente, observando-se que ambos os tratamentos atenderam às exigências nutricionais de proteína bruta $(150 \mathrm{~g} / \mathrm{dia})$. Os consumos médios de NDT foram de 807,88 e 918,23 g/dia, para os tratamentos com grãos de milho e de sorgo, respectivamente. Apenas os tratamentos contendo sorgo supriram as exigências nutricionais de

Tabela 5 - Médias e coeficientes de variação dos consumos de matéria seca (CMS), em g/dia, \%PV e g/kg de peso metabólico (\%PV0,75), de nutrientes digestíveis totais (CNDT) e de proteína bruta (CPB), conversão alimentar, eficiência alimentar (em \%), pesos inicial e final, ganho total (em kg) e ganho médio diário (GMD), em gramas/dia, para cordeiros em confinamento recebendo dietas à base de feno de capim-braquiária (Brachiaria brizantha) e grãos de milho ou sorgo, secos ou ensilados úmidos

Table 5 - Averages and coefficients of variation of intakes of dry matter (IDM), in g/day, \%BW and g/kg of metabolic weight (BW ${ }^{0.75}$ ), total digestible nutrients (ITDN) and crude protein (ICP), feed conversion, feed efficiency (\%), initial and final weights, total weight (in kg) and average daily gain (ADG), in grams/day, for feedlot lambs fed diets with Brachiaria hay (Brachiaria brizantha) and different sources of grain

\begin{tabular}{|c|c|c|c|c|c|}
\hline \multirow[t]{2}{*}{ Item } & \multicolumn{2}{|c|}{$\begin{array}{l}\text { Grãos de milho } \\
\text { Corn grains }\end{array}$} & \multicolumn{2}{|c|}{$\begin{array}{l}\text { Grãos de sorgo } \\
\text { Sorghum grains }\end{array}$} & \multirow[t]{2}{*}{ CV (\%) } \\
\hline & $\begin{array}{l}\text { Secos } \\
\text { Dried }\end{array}$ & $\begin{array}{l}\text { Ensilados } \\
\text { Ensiled }\end{array}$ & $\begin{array}{l}\text { Secos } \\
\text { Dried }\end{array}$ & $\begin{array}{l}\text { Ensilados } \\
\text { Ensiled }\end{array}$ & \\
\hline $\begin{array}{l}\text { CMS (g/dia) } \\
\text { DMI (g/day) }\end{array}$ & $1135,06 \mathrm{~b}$ & $1106,41 \mathrm{~b}$ & $1250,91 \mathrm{a}$ & $1332,03 \mathrm{a}$ & 7,76 \\
\hline $\begin{array}{l}\text { CMS }(\% \mathrm{PV}) \\
D M I(\% B W)\end{array}$ & 3,46 a & 3,41 a & 3,55 a & 3,76 a & 3,04 \\
\hline $\begin{array}{l}\text { CNDT (g/dia) } \\
\text { TDNI (g/day) }\end{array}$ & 835,52 a & 780,24 a & 899,78 a & 936,68 a & 10,85 \\
\hline $\begin{array}{l}\text { CPB (g/dia) } \\
\text { CPI (g/day) }\end{array}$ & 195,46 a & 205,24 a & 227,66 a & 229,24 a & 10,74 \\
\hline $\begin{array}{l}\text { Conversão alimentar } \\
\text { Feed conversion }\end{array}$ & $5,72 \mathrm{~b}$ & $6,13 \mathrm{~b}$ & 5,29 a & $5,84 \mathrm{~b}$ & 8,25 \\
\hline $\begin{array}{l}\text { Peso final } \\
\text { Final weight }\end{array}$ & $32,78 \mathrm{~b}$ & $32,75 \mathrm{~b}$ & 34,98 a & 35,40 a & 3,74 \\
\hline $\begin{array}{l}\text { Ganho total } \\
\text { Total gain }\end{array}$ & $7,93 \mathrm{~b}$ & $7,22 \mathrm{~b}$ & 9,47 a & 9,12 a & 11,47 \\
\hline $\begin{array}{l}\text { GMD } \\
A D G\end{array}$ & $198,33 \mathrm{~b}$ & $180,42 \mathrm{~b}$ & 236,67 a & 227,92 a & 11,29 \\
\hline
\end{tabular}

\footnotetext{
${ }^{1}$ Médias seguidas por letras iguais na mesma linha não diferem $(P>0,05)$ pelo teste Tukey.
}

${ }^{1}$ Means followed by same letters, in the same row, did not differ $(P>0.05)$ by Tukey test. 
NDT sugeridas para ganhos de $200 \mathrm{~g} / \mathrm{dia}$, o que pode ser comprovado pelos resultados de ganhos médios diários (GMD) apresentados na Tabela 5.

O tratamento com grãos secos de sorgo proporcionou a melhor conversão alimentar $(\mathrm{P}<0,05)$, enquanto os demais (grãos úmidos de milho ou sorgo e grãos secos de milho) não diferiram $(\mathrm{P}>0,05)$ entre si.

Camurça et al. (2002) observaram consumo, conversão alimentar e ganhos de peso médios inferiores aos observados neste experimento, provavelmente em razão da idade (aproximadamente 10 meses) e do peso inicial dos animais $(26,5 \mathrm{~kg})$, que estiveram muito acima da faixa de peso e idade recomendada pela EMBRAPA (1997) para entrada dos cordeiros no sistema de confinamento (15 a $18 \mathrm{~kg}$ PV e 4 e 6 meses de idade), com o objetivo de boas respostas em produtividade animal.

Os animais que receberam grãos de sorgo, secos ou ensilados úmidos, apresentaram maiores $(\mathrm{P}<0,05)$ ganhos de peso médios que aqueles alimentados com grãos de milho, secos ou ensilados úmidos, no período em que o feno de capim-braquiária (Brachiaria brizantha) foi utilizado. Ressalta-se que neste período a relação volumoso:concentrado foi de 30:70, o que, provavelmente, resultou em ambiente ruminal desfavorável, notadamente no caso dos grãos de milho, secos ou ensilados úmidos, e dos grãos de sorgo úmidos. Os grãos secos de sorgo certamente apresentaram menor velocidade e extensão de degradação e causaram menores efeitos sobre o ambiente ruminal, resultando em melhor conversão alimentar (Tabela 5).

Os grãos de sorgo, secos ou ensilados úmidos, proporcionaram maiores valores de ganho de peso, com média de $232,30 \mathrm{~g} / \mathrm{dia}$, e não diferiram entre si. Da mesma maneira, Peixoto et al. (2003) avaliaram o grão seco ou a silagem de grãos úmidos de sorgo como fonte energética para bezerras e concluíram que as silagens de grãos úmidos substituíram eficientemente os grãos secos de sorgo no concentrado, com médias de ganho de peso semelhantes ( $814 \mathrm{~g} / \mathrm{dia})$.

Reis et al. (2001) também avaliaram o desempenho de cordeiros terminados em confinamento, consumindo silagens de milho com grãos com alta umidade ou grãos de milho hidratados em substituição aos grãos secos e registraram ganhos de peso médios de 123,70 e $160,90 \mathrm{~g} / \mathrm{dia}$ e conversões de 3,94 e 3,07 para as dietas com grãos secos de milho e com silagens de grãos úmidos de milho, respectivamente. Os autores atribuíram a melhor resposta dos animais alimentados com $100 \%$ de silagem de grãos úmidos de milho à composição do amido e ao processo de gelatinização do amido, decorrente da ação dos ácidos orgânicos advindos do processo de ensilagem. O amido, após ser gelatinizado, possui maior capacidade de absorção de água, o que facilita a ação digestiva, resultando em melhor aproveitamento pelos microrganismos ruminais.

Entretanto, as médias de ganho de peso obtidas por Reis et al. (2001) foram inferiores às registradas neste ensaio, de 133,33 e 167,62 g/dia, para grãos de milho secos ou úmidos, associados ao capim-elefante (Tabela 4), e de 180,42 e 198,33 g/dia, para grãos de milho secos e úmidos, associados ao feno de capim-braquiária (Brachiaria brizantha) (Tabela 5). Talvez o menor peso dos cordeiros $(9,3 \mathrm{~kg})$ no início do confinamento tenha comprometido o ganho de peso médio diário pelo maior estresse dos animais. Contudo, os melhores valores de conversão alimentar encontrados por Reis et al. (2001), em comparação aos 6,37 e 5,57, para grãos de milho secos ou úmidos associados ao capim-elefante (Tabela 4), e aos 6,13 e 5,72, para grãos de milho secos e úmidos, associados ao feno de capim-braquiária (Tabela 5), possivelmente estiveram relacionados ao uso de cordeiros com melhor potencial de ganho de peso (cruzados Bergamácia x Corriedale), enquanto, neste experimento, os cordeiros não possuíam raça definida.

As formas de armazenamento dos grãos de milho e de sorgo proporcionaram consumo de matéria seca e desempenho semelhantes nos ovinos submetidos a dietas à base de capim-elefante com relação volumoso:concentrado de 50:50 (Tabela4). Possivelmente, nesta relação volumoso:concentrado, o processo de ensilagem, associado à colheita antecipada, favoreceram os processos digestivos do animal, como resultado do tratamento ácido do material e do maior teor de umidade do alimento, principais responsáveis pelos melhores resultados obtidos com grãos de milho e de sorgo ensilados úmidos.

Entretanto, em situações de maior utilização de concentrado, como na relação volumoso:concentrado 30:70 (Tabela 5), além dos efeitos proporcionados pelo processo de ensilagem e pela antecipação da colheita dos grãos, o ambiente ruminal proporcionado pelas dietas é de extrema importância, visto que os grãos secos de sorgo demonstraram superioridade sobre as demais formas de armazenamento.

\section{Conclusões}

Em dietas com proporção volumoso:concentrado 50:50, as silagens de grãos de milho e de sorgo úmidos proporcionaram ganho de peso e conversão e eficiência alimentares melhores em ovinos jovens terminados em confinamento que aquelas contendo grãos secos.

Em dietas com proporção volumoso:concentrado 30:70, os grãos de sorgo secos proporcionaram melhor conversão alimentar que os grãos de milho secos e as silagens de grãos de milho e de sorgo úmidos. 


\section{Literatura Citada}

AGRICULTURAL AND FOOD RESEARCH COUNCIL - AFRC. Energy and protein requirements of ruminants. Cambridge: University Press, 1993. 159p.

ALMEIDA JR., G.A.; COSTA, C.; MONTEIRO, A.L.G. et al. Desempenho e características das carcaças de cordeiros alimentados com silagem de grãos úmidos de milho em sistema creep feeding. In: REUNIÃO ANUAL DA SOCIEDADE BRASILEIRA DE ZOOTECNIA, 39., 2002, Recife. Anais... Recife:Sociedade Brasileira de Zootecnia [2002] CD-ROM. Nutrição de ruminantes. NUT-832.

BERNDT, A.; HENRIQUE, W.; LANNA, D.P.D. et al. Milho úmido, bagaço de cana e silagem de milho em dietas de alto teor de concentrado. Composição corporal e taxas de deposição dos tecidos. Revista Brasileira de Zootecnia, v.31, n.5, p.21052112,2002

CAMURÇA, D.A.; NEIVA, J.N.M.; PIMENTEL, J.C.M. et al. Desempenho produtivo de ovinos alimentados com dietas à base de feno de gramíneas tropicais. Revista Brasileira de Zootecnia, v.31, n.5, p.2113-2122, 2002.

CARVALHO, F.F.R.; MEDEIROS, G.R.; ALVES, K.S. Nutrição e alimentação de ovinos em confinamento. In: FERREIRA, R.A.; VELOSO, C.M.; RECH, C.L.S. et al. (Eds.). Nutrição animaltópicos avançados. Itapetinga: Universidade Estadual do Sudoeste da Bahia, 2003. p.176-213.

COSTA, C.; ARRIGONI, M.D.B.; SILVEIRA, A.C. et al. Silagem de grãos úmidos. In: SIMPÓSIO SOBRE NUTRIÇÃO DE BOVINOS, 7., 1999, Piracicaba. Anais... Piracicaba: Fundação de Estudos Agrários Luiz de Queiroz, 1999. p.69-87.

EMPRESA BRASILEIRA DE PESQUISA AGROPECUÁRIA EMBRAPA. Terminação de borregos em confinamento no Nordeste do Brasil. Sobral: 1997. 24p. (Circular Técnica, 12).

GARCIA, I.F.F.; PEREZ, J.R.O.; TEIXEIRA, J.C. et al. Desempenho de cordeiros Texel x Bergamácia, Texel x Santa Inês e Santa Inês puros, terminados em confinamento, alimentados com casca de café como parte da dieta. Revista Brasileira de Zootecnia, v.29, n.2, p.564-572, 2000.

ÍTAVO, C.C.B.F. Silagens de grãos úmidos de milho e de sorgo: padrão de fermentação, composição química, valor nutricional e desempenho em ovinos. Campo Grande: Universidade Federal de Mato Grosso do Sul, 2004. 64p. Dissertação (Mestrado em Ciência Animal - Produção Animal) Universidade Federal de Mato Grosso do Sul, 2004.

JOBIM, C.C.; CECATO, U.; CANTO, M.W. Utilização de silagem de grãos de cereais na alimentação animal. In: SIMPÓSIO SOBRE PRODUÇÃO E UTILIZAÇÃO DE FORRAGENS CONSERVADAS, 1., 2001, Maringá. Anais... Maringá: Universidade Estadual de Maringá, 2001.p.146-176.
JOBIM, C.C.; REIS, R.A. Produção e utilização de silagem de grãos úmidos de milho. In: REUNIÃO ANUAL DA SOCIEDADE BRASILEIRA DE ZOOTECNIA, 38., 2001, Piracicaba. Anais... Piracicaba: Sociedade Brasileira de Zootecnia, 2001. p. $912-927$

OLIVEIRA, R.P.; FURLAN, A.C.; MOREIRA, I. et al. Valor nutritivo e desempenho de leitões alimentados com rações contendo silagem de grãos úmidos de milho. Revista Brasileira de Zootecnia, v.33, n.1, p.146-156, 2004

PEIXOTO, L.A.O.; ALVES FILHO, D.C.; RESTLE, J. et al. Grão seco ou silagem de grão úmido de sorgo como fonte energética para bezerras. In: REUNIÃO ANUAL DA SOCIEDADE BRASILEIRA DE ZOOTECNIA, 40., Santa Maria, 2003. Anais... Santa Maria: Sociedade Brasileira de Zootecnia, [2003] CD-ROM. Nutrição de ruminantes. NUT-252.

PHILIPPEAU, C.; MONREDON, F.D.; MICHALET-DOREAU, B. Relationship between ruminal starch and the physical characteristics of corn grain. Jounal of Animal Science, v.77, p.238-243, 1999 .

REIS, W.; JOBIM, C.C.; MACEDO, F.A.F. et al. Desempenho de cordeiros terminados em confinamento, consumindo silagens de milho de grãos com alta umidade ou grãos de milho hidratados em substituição aos grãos de milho seco da dieta. Revista Brasileira de Zootecnia, v.30, n.2, p.596-603, 2001.

SANTOS, C.P.; FURTADO, C.E.; JOBIM, C.C. et al. Avaliação da silagem de grãos úmidos de milho na alimentação de equinos em crescimento: valor nutricional e desempenho. Revista Brasileira de Zootecnia, v.31, n.3, p.1214-1222, 2002.

SARTORI, J.R.; COSTA, C.; PEZZATO, A.C. et al. Silagem de grãos úmidos de milho na alimentação de frangos de corte. Pesquisa Agropecuária Brasileira, v.37, n.7, p.1009-1015, 2002.

SILVA, D.J.; QUEIROZ, A.C. Análise de alimentos (Métodos químicos e biológicos). 3.ed. Viçosa, MG: Universidade Federal de Viçosa, 2002. 235p.

UNIVERSIDADE FEDERAL DE VIÇOSA - UFV. SAEG-Sistema de análises estatísticas e genéticas. Versão 8.0 (manual do usuário). Viçosa, MG: Universidade Federal de Viçosa, 2000. $142 \mathrm{p}$.

VALADARES FILHO, S.C.; ROCHA JR., V.R.; CAPELLE, E.R. Tabelas brasileiras de composição de alimentos para bovinos. Viçosa, MG: Universidade Federal de Viçosa, 2002. $297 \mathrm{p}$. 